\title{
The Hazards of Measuring the Drive to Breathe
}

\author{
Neil S. Cherniack \\ New Jersey Medical School, Newark, N.J., USA
}

In this issue of Respiration, Moura et al. [1] report on the effects of consecutive nights of nasal continuous positive air pressure on the occlusion pressure and ventilatory response to $\mathrm{CO}_{2}$ in 12 patients with obstructive sleep apnea in an attempt to determine changes in ventilation drive, i.e. chemoreceptor responses.

Theoretically, in hypercapnic patients, nasal continuous positive air pressure might improve sensitivity to $\mathrm{CO}_{2}$ by reducing resting levels of $\mathrm{PCO}_{2}$, which in turn would lead to a fall in bicarbonate levels. In normocapnic patients, such as those studied by Moura et al. [1], relief of sleepiness might improve $\mathrm{CO}_{2}$ responses [2]. The results of Moura et al. [1] were inconclusive; the occlusion pressure increase with $\mathrm{CO}_{2}$ was greater but the ventilatory response was not.

Moura et al. [1] state that the occlusion pressure response (the pressure generated at the mouth during inspiration in the first $100 \mathrm{~ms}$ after airway occlusion) is a more sensitive measure of drive than ventilation. However, there is little or no evidence to support this. The occlusion pressure response was conceived as a way to measure chemosensitivity in the face of impaired lung mechanics, since poor mechanics could depress the response to ventilation even when the sensitivity of the chemoreceptors was normal [3-5]. The occlusion pressure was assumed to reflect the 'net respiratory pressure' generated by the respiratory muscles under isometric conditions, and this is less affected by increased airway resistance than ventilation. However, in the study of Moura et al. [1], lung function is reported to be normal. Occlusion pressure does depend on the ability of the respiratory muscles to generate force and this in turn depends on their length. A decrease in functional residual capacity with the treatment of sleep apnea could give rise to an increase in occlusion pressure, but there is no reason why this should have occurred, and in fact, resting occlusion pressure was unchanged.

The real problem in measuring chemosensitivity, I believe, is the difficulty in measuring the drive to breathe by any technique and particularly by the technique used in this study. Great care is needed to obtain reliable measurements.

In this study, $8 \% \mathrm{CO}_{2}$ in $42 \% \mathrm{O}_{2}$ was breathed and measurements were made before and between the 4 th and 5th minute of $\mathrm{CO}_{2}$ breathing. To be valid, both before and after measurements have to be made in the steady state. There is no evidence that this is true for either one [6].

Initial measurements were made with the subjects apparently breathing room air and not with $42 \% \mathrm{O}_{2}$. The enriched $\mathrm{O}_{2}$ mixture breathed might have affected breathing, albeit slightly. More importantly, it has been known for some time that a steady state is not achieved during $\mathrm{CO}_{2}$ breathing for well over $20 \mathrm{~min}$, particularly with the high concentration of $8 \%$ used in this study. Also, the rate of equilibration will vary not just with the dynamics of the ventilatory response but will also depend on the magnitude and dynamics of the systemic circulatory and cerebral blood flow response. More accurate and reproducible

\begin{tabular}{ll}
\hline KARGER & ( ) 2001 S. Karger AG, Basel \\
Fax +41 613061234 & 0025-7931/01/0683-0240\$17.50/0 \\
$\begin{array}{l}\text { E-Mail karger@karger.ch } \\
\text { www.karger.com }\end{array}$ & $\begin{array}{l}\text { Accessible online at: } \\
\text { www.karger.com/journals/res }\end{array}$
\end{tabular}

Neil S. Cherniack, MD

Office of the Dean, UMDNJ - New Jersey Medical School

185 South Orange Avenue

Newark, NJ 07103-2714 (USA)

Tel. +1973972 7937, Fax +1973972 7104, E-Mail cherniac@umdnj.edu 
measurements probably could have been achieved using a rebreathing technique.

However, even with the rebreathing method, care must be taken to perform measurements in the same state, i.e. at the same time of the day, at the same time after meals and making sure to the greatest possible extent that environmental and psychological disturbances are minimal.
Despite the inconclusiveness of the results from the above-mentioned study, data on the drive to breathe as sleep apnea is treated can be extremely valuable in sorting out differences in the response to treatment and in selecting the appropriate treatment for different individuals.

\section{References}

1 Moura SMT, Bittencourt LR, Bagnato MC, Lucas SR, Tufik S, Nery LE: Acute effect of nasal continuous positive air pressure on the ventilatory control of patients with obstructive sleep apnea. Respiration 2001;68;243-249.

2 Stradling JR: Sleep-related breathing disorders. 1. Obstructive sleep apnoea: Definitions, epidemiology, and natural history. Thorax 1995 ; 50:683-689.
3 Altose MD, Kelsen SG, Stanley NN, Levinson RS, Cherniack NS, Fishman AP: Effects of hypercapnia on mouth pressure during airway occlusion in conscious man. J Appl Physiol 1976;40:338-344.

4 Whitelaw WA, Derenne JP, Milic-Emili J: Occlusion pressure as a measure of respiratory center output in conscious man. Respir Physiol 1975;23:181-199.
5 Lederer DH, Altose MD, Kelsen SC, Cherniack NS: Comparison of occlusion pressure and ventilation responses. Thorax 1977;32:212-220.

6 Lambertsen CJ, Owen SG, Wender H, Stroud MW, Lurie AA, Lochner W, Clark GF: Respiratory and circulatory control during exercise at 1.4- and 2.0-atmospheres inspired $\mathrm{PO}_{2}$. J Appl Physiol 1959;14:966-982. 